\title{
OPTIMAL LEARNING CONDITIONS FOR MASTERS AND DOCTOR OF PROFESSIONAL PRACTICE MĀORI LEARNERS
}

\author{
Kelli Te Maihāroa, Griffin Manawaroa Leonard, \\ and Tonga Karena
}

\author{
Ko te pae tawhiti whāia kia tata, ko te pae tata whakamua kia tina \\ Seek to bring distant horizons closer, to sustain and maintain those that have arrived
}

$\mathrm{MIHI}$

\section{Acknowledgements}

We wish to appropriately honour the eight Māori research participants that shared their wisdom, knowledge and time with us. Your unique experiences and voices are central to this research and to enhancing and shaping a more responsive postgraduate programme for future Māori learners. Also, a big mihi to Janine Kapa and her team at the Kaitohutohu Office of Māori Development at Otago Polytechnic, for their ability to keep the waka moving forward, through sometimes choppy waters. Your positive leadership and relentless focus on supporting and advancing Māori learners to achieve educational success as Māori is of significant importance. Kā mihi aroha ki a koutou katoa.

\section{INTRODUCTION}

In accordance with Te Tiriti o Waitangi, Otago Polytechnic (OP) is focused on Māori learner engagement, retention and success. The strategic merger of all 16 polytechnics within Aotearoa New Zealand into one organisation known as Te Pükenga, is a move to ensure that service provision works well and responds with excellence to the aspirational needs of Māori learners, whānau and iwi.This research was undertaken to explore the optimal learning conditions for Māori learners in the two relatively new programmes to Capable NZ professional practice suite; the Master of Professional Practice and Doctor of Professional Practice programmes. As part of the Otago Polytechnic College of Work-Based Learning, Capable NZ offers New Zealand Qualification Authority accredited qualifications without returning to lectures, through work or community-based learning. Capable NZ offers a variety of online learning programmes from certificates, diplomas, degrees and now postgraduate options. Māori learners make up between 25 to 30 per cent of Capable NZ learners, and as priority learners within a new suite of postgraduate programmes, it was important to undertake research to ensure that their learning and cultural needs were being met.

This research sets out to explore the Māori learner experiences within the Master and Doctor of Professional Practice programmes at Capable NZ in an attempt to highlight (i) the optimal learning conditions, as identified by Māori learners, and (ii) what areas may need further attention to fit the learning needs of Māori tauira. This chapter will highlight two key areas of findings from this research; firstly, what are the optimal learning conditions for post graduate Māori learners within the Polytechnic environment; and secondly, what areas may require further attention 
to fit the learning needs of tauira. Interviews were semi-structured and typically lasted around 20 minutes. Two Māori contractors were hired to undertake the interviews and initial analysis of the eight interviews, including two interviews in te reo Māori. The article within this publication entitled "Ko te mouri o te mahi te mouri o te ora" explores te reo Māori learners postgraduate experience, whilst this article considers the six interviews undertaken in English, with Māori learners participating in Capable NZ's Master of Professional Practice (MPP) and Doctor of Professional Practice (DPP) programmes.

The following sections outline recurring themes among interviewee responses from the English interviews. Both commonality and contrast among responses is noted, with an emphasis on the interviewee quotations drawn on at length in an attempt to maintain the participants' voice throughout and to ensure that Māori learner voice is at the forefront of this report. One of the primary themes is the relationship between the learner, facilitator and mentor, which also considers the connections beyond these relationships. There are also four primary themes that fall under the opportunity to optimise Māori learner experiences. These include learning relationships and expectations, te reo Māori/bilingual material, resources and processes, production and assessment of knowledge and the highlights of the Master's and Doctoral framework. The concluding section provides five suggestions for further change practice, which includes access, agency, creating a sense of belonging, fostering Māori identity, and Māori staff.

\section{RELATIONSHIPS BETWEEN FACILITATOR, MENTOR AND LEARNER}

Strong positive relationships between learners and facilitators support excellent learning outcomes. All interviewees believed that a strong relationship between the learner, facilitator and academic mentor was key to enjoying and succeeding in either the MPP or DPP. All but two respondents felt that they had a positive relationship with their facilitator and mentor. Important qualities in facilitators and mentors that were identified were a willingness to be flexible and allow the learner to have autonomy, valuing (or even understanding or subscribing to) the perspective/ experience that a Māori learner brings to their study, possessing content specific knowledge, offering pastoral care and encouragement, as well as communicating regularly with the learner.

...I think it's his professionalism and his desire to see us achieve to a high level which has encouraged him to gain a huge amount of knowledge so that he understands [my pedagogical needs] as best he can... And, and he'll go and find ways to communicate ideas to me in a way that he thinks I'll understand. And I have so much admiration and respect for him because of that... because I can't be bothered with all that stuff, with the academic stuff. It holds no interest for me, I don't care. I don't care to know all that theory. It just feels like a lot of times, it just clogs up my brain. And, so, he, he knows that theory, and I'll talk to him about something. He'll say, "Oh, that's exactly this", and he'll name it for me. And then I'll go off and do my own research. And it's been amazing.

Mark seems to have a big knowledge of some of the key texts that l've already got but haven't spent a long time looking at. So, that connection. I don't know, once he, when he started talking it gave me a little bit of security because he's not Māori, but it gave me a sense of, OK, he can manage what I think I'm doing because he's informed about some of the texts that I am using and he knows some of the key names, I guess, because of the work that with other learners that he's done.

These two quotes pertain to a mentor who is not Māori but is a very experienced tertiary educator and is interested in Māori learners as culturally located students within the learning journey. The learners have identified some of the underlying aspects of whakawhanaukataka, where the learning relationship is a two-way process, built on a foundation of high expectations and exploring possible meanings together. By developing a trusting and respectful learner/mentor relationship, the learner was able to be themselves, to share their opinions and barriers to theories, but to also be open to learning new models and concepts when re-packaged to make sense and meaning 
of them. A contrasting view was provided by the two following interviewees who stated they did not have a strong relationship with their facilitator, although one learner indicated that they played a part in these shortcomings. It is important for both learner and facilitator that each party takes responsibility for their own part in the learning journey and work towards a respectful learner/mentor relationship. Thus, all but one interviewee felt they had positive relationships with their facilitator.

The facilitator I had was, she was very accommodating and very knowledgeable. The relationship that we had wasn't great, but I completely accept that as being a failing from, from my perspective to be quite honest. My facilitator was always open to new ways of thinking and new ideas to, to new possibilities. And when I challenged her on a couple of things, she went and sourced information and came back with a bit of clarity for herself around there... So, insofar as a facilitator that I had, yeah, I'm very, very happy that she played the game.

This learner identified that the underlying foundation of the relationship was not overly strong, which may indicate that there were cultural differences (although this is not explicitly referred to). The learner provides some reassurance that the facilitator was open to new possibilities, but it is the facilitator's role to engage in robust dialogue for the benefit of the Māori learner, not the learner's job to provide new ideas and approaches for the facilitator.The final above sentence suggesting that the facilitator 'played the game' may infer that the facilitator did the minimum to keep the learner happy or that the facilitator may not have had the tools to develop metacognitive strategies for a successful learning experience. However, this does not necessarily mean that a given facilitator will have the skills or resources to ensure cultural safety or assist in the implementation of kaupapa Mãori research. This is further evidenced in the following response which highlights the gap between knowing how to select appropriate culturally appropriate content and also draw on a kaupapa Māori approach to work successfully with diverse learners.

She [my facilitator] allowed stuff to happen and acknowledged that there was difference [in terms of how Māori might approach their research] and encouraged it but wasn't in the position to enable it... she didn't have the tools herself to enable that to happen, to say, "Okay, you're doing this and that's great but now you need to go here, or consider this...

For the one interviewee who did not have a positive relationship with their facilitator for reasons out of their control, this was clearly a very disruptive state of affairs. The negative nature of this relationship appears to be based on personal clashes or health issues, rather than due to potential broader issues such as a disregard for kaupapa Māori research or anything similar.

I felt that the relationship between the academic mentor and facilitator combined completely put me off my Master's... So, there was a personal issue that happened with my facilitator which impacted the relationship between the three of us, which had me backing out really quickly... but because a personal issue became apparent for the facilitator, it impacted on our relationship moving forward in terms of my Master's. That's probably the best way I can explain it.

For this learner, there was an overriding negative relationship between the learner and her facilitator that could not be mended, resulting in the learner exiting the Master's programme. The process of backing out implies that the learner did not feel safe and that the demise of this relationship hampered the learner/facilitator engagement process. An effective and robust professional learning relationship is an essential ingredient for learner success and well-being. A learner-centred pathway aims to empower learners to make their own decisions about their learning programme, learning experiences and those in positions to facilitate their learning. It would seem that in this instance, the facilitator was oblivious to the strain and impact a failing relationship can have on the learning environment and final outcome. 
Interviewees generally reported positively on how the structure of Capable NZ's programme allowed them to find a facilitator that suited their needs. All respondents who were asked whether they had been offered the opportunity to work with a Mãori facilitator replied that they had been given this opportunity.

...I think what is different in the Capable process is that traditionally a PhD will be, who has a knowledge in this area, and it's usually like content knowledge and such... it's so discipline-specific. But I think what really comes to the forefront in Capable is, who is a supervisor that kind of sees the world in a similar light to you, who has a similar philosophy toward things... what knowledge paradigm, and what do they value?... I couldn't work with somebody who sought well, you know, Western scientific positive truth, because it's not my belief. And I think that's where you know, where you come in with Capable, that facilitation role is so important.

For me personally, now I don't know if anyone else gets this opportunity, l've been able to... I guess, tailor the program and things that work best for me. I guess my approach towards how I was going to articulate the particular research topic, and how that falls into the recommended criteria... So that's been a highlight. I've been able to, I guess, hand pick a facilitator and academic mentor who will not only assist me but better my research, my mahi. And l'll learn a lot from those people. So that's been a positive outcome for me so far.

The two above learners have identified how important and empowering it is to be offered a facilitator and one that fits their world view. The opportunity to choose a Māori facilitator provides a 'cultural fit' for Māori learners who would expect the foundational basis of their learning/facilitation relationship is grounded within te ao Māori, where Māori beliefs, culture and language form a shared understanding. The process of inviting the learner to identify from the outset what kind of facilitator would be a good fit for them, empowers the learner to express their mana motuhake, agency and self-determination to create and manage their own learning conditions from the start.

A number of interviewees touched on the fact that they had pre-existing relationships with their facilitators or potential facilitators. There was a sense that this added a certain dimension to the programme. One interviewee found this to be positive, as a pre-existing relationship meant the parties knew how each other worked, while another found it could make things awkward if things were not going well in terms of the programme of study. Relatedly, some of those who were employees of OP Capable NZ noted that this gave them a base network beyond their facilitator to discuss their studies with. The need for a broad support network is discussed further below.

Well, I suppose I should preface that the facilitator is also a colleague. So, you know, yeah. We did have a prior relationship and she sort of knew something about me and how I work, and a fair idea of how to attempt to manage that relationship...

But I think that the relationship between the mentor and the facilitator is so important. And that's something that I wanted to talk about too was, so when you're internal and when you're being assessed, sorry, when you're working and studying together, you've got a relationship with those people [facilitator and mentor] outside of your academic role, it can be quite challenging.

The intersection between colleagues and learner/facilitator relationship is an interesting point and spotlights potential complexities and complications between the two relational settings. This raises the question of what does it mean for a Māori learner when their colleague becomes their facilitator and how does this impact on their mentor/student relationships in terms of creating optimal learning environment? On one hand, the learner and colleague know each other and would have a respectful working relationship, if the learner had a choice in who their facilitator could be. What is alluded to above is the challenge of managing this relationship at times and the potential change in power when being assessed by colleagues. The learner, including a staff learner, does not 
have a say in who is chosen to assess them. The assessment process is a crucial and delicate part of the learning journey, and it is hoped that the staff learner and assessor have a trusting and respectful working relationship, and that the assessment process is robust to withstand any internal or external scrutiny. Interviewees reported that they communicated with their facilitators and mentors in a number of ways, including email, phone calls, onlineconferencing and in-person meetings.

Yeah, I think, the grounding has been having someone in this building to talk to. So, not just when it was you, but also the staff that I knew, like, l've had a side chat with Tahu... I think we've used emails and Zoom, which is a... good face to face thing. It's definitely helpful. But I am getting, it's filling my cup or enriching my wairua, or whatever it is, meeting [in-person] with Mark and, and, it's getting regular and that's really good for me.

So, I tend to respond to emails, quite regularly. It's something that you can't really avoid at the moment. You know, you've got the devices that follow you all over the place. So, I've had a discussion when we first started with my facilitator on what would be the best form of communication that would work for me. And I said "emails". If something was pressing and needed to happen immediately, my facilitator's being open and given me her personal contact information to contact them. My facilitator's been able to facilitate hui online via Teams and Zoom and also being the first point of call when I have any questions.

The opportunity for the learner to reach out to their facilitator when they need to and in a variety of communication methods is an important factor to maintain the learner-facilitator relationship. Personal contact details and email seems to be an agreeable method to make semi-urgent contact, whilst Zoom or Teams is the preferred online platform for virtual kanohi ki kanohi connection.

\section{RELATIONSHIPS BEYOND THE LEARNER-FACILITATOR-MENTOR RELATIONSHIP}

In working to achieve excellent outcomes for Māori learners and communities, there is also an expectation that educational services improve for the betterment of Māori. While interviewees all believed that the relationship a learner had with their facilitator and mentor was of vital importance, the commentary also highlights that it is unlikely that any one facilitator or mentor will have the skills and resources to fully support an individual Māori learner. Some of this is simply a reality of the fact that learners require support from a number of sources, such as facilitators, friends and whānau, as well as colleagues and peers undertaking the same course of study. However, for Māori learners, this is particularly apparent.

The need to ensure "Māori are enjoying and achieving educational success as Māori" is widely accepted.' As will be discussed further below, interviewees reported that facilitators usually valued a learner's Māori identity and culture and attempted to scaffold a course of study in such a way that recognised kaupapa Māori approaches to research and the learner's individual background. A familiar theme is the need to develop whanaukataka, including relationships that are wider than just the learner/facilitator.

...I know it's a bit hard because we all start at different times but like a timatanga kind of hui. So, you're all in the first three months, let's have a hui. Let's have a coffee. I mean, we do we do a pōwhiri for the students when they start.... then you've got that whakawhanaungatanga again.

I think for me being on the ground here, I think that, it's a weird thing, but the office, there's not a lot of sense of mana whenua, tangata whenua, in that office where Capable is ... you know that, that's just a little thing. And there's no point in having window dressing if there's nothing behind it. 
This feedback identifies a lack of cultural support within Capable NZ processes and spaces from the point of entry into the programme. As Capable NZ learners are spread throughout Aotearoa and further afield and there is no set programme start date, the opportunity to have a pōwhiri for each student is a challenge but could be further investigated with learners to explore what this may look like within an online setting. There is currently no Māori postgraduate space, which can lead to cultural isolation for learners without a Māori korowai around them. One learner suggested that the opportunity to create an online space may also provide access to a collective of kaupapa Māori resources: "I think having a community in the post grad suite, you know, within kaupapa Māori, for instance, who, you know, is a pool of resources".

There were a number of comments made about the need to develop wider cultural support within Capable NZ, including the opportunity to acquire outside support if needed. One learner identified the need for more Māori staff to support the programme to flourish culturally and not rely on "... one or two people, like yourself Kare, you can't do everything for Māori. And nor should you be expected to do that. We actually need more Māori people, and resources to support this programme." The lack of Māori staff could also be a factor for another learner who sought support from outside Capable NZ: "I don't think l'd like it as much [if I had to rely on Capable for all my support] ... I find that a lot of the people at Capable are not people I find easy to communicate with."'This point was echoed by another learner who felt culturally unsafe at times and responded by ensuring that s/he had access to kaumātua support from their own iwi. The learner raises a really valid point about cultural safety, kaumātua support and recognition by Capable NZ for this vital support.

...I think for Māori that it would be really good to have someone in a cultural space that can provide you with some cultural support. That was something I did struggle with... I felt inside of it [the Capable process], there were times that I felt culturally unsafe. So, I did talk to them about that, and I said what I was going to do was initiate my own cultural safety, or just even somewhere I could go to a kaumätua that was local that I could access, to make sure that what I'm doing or what I'm talking about in terms of our protocols, because we're different to you guys down here. So, it has to be somebody that has the same, you know from your own area, from your iwi. That was really important for me... He [the kaumātua in question] was willing to do that, but then where is the acknowledgement for him inside of that too?

Indeed, the formation of relationships is not only necessary in order to support academic success in a narrow sense. Rather, the formation of relationships is a valuable outcome of the process, built on kinship and whakawhanaukataka, where deep learning and insights are gained about their own and other Māori communities.

The highlights have been around making surprising connections, unexpected connections, as in, like, starting to know people. So, I met Tare with you at a cafe down in the Hub having a coffee. So, it's that kind of unexpected connection that has linked me. So, when he was there, at the Parihaka commemoration. I knew who he was. Now, you know, the awareness of who's around, so it's not directly related to what l'm studying, but it's those whakawhanaukataka connections that happen because I'm involved in a te ao Māori version of it, I guess. So that would be a highlight that it's a definite highlight and just, I guess, that wonderful connection between Taranaki and Dunedin, which focuses on what l'm doing my project on. You know, it's just a beautiful connection, you couldn't plan it. I mean, you probably could, but it wouldn't be the same.

I'm surrounded by some incredibly strong, intelligent, educated Māori appearing. Like, if I look at my friend group... I feel really, really fortunate. Like at the other day, I was sort of going through this concept, and I wasn't quite sure where I was going... So, I just called a few of my mates together, and we just sat down and we just sort of hashed 
out this idea. And I value that I can do that, like I'm hugely well supported. So, I'm well supported in that space. And in some from Ngāti Awa, some from Ngāi Tuhoe, Whakatōhea, Tüwharetoa this beautiful collection of incredible humans and, and we discuss ideas and we philosophise, and we argue and debate and shout and rant and laugh, and that's beautiful...

\section{VALUING MĀORI CULTURE, IDENTITY, LANGUAGE AND APPROACHES TO RESEARCH}

To ensure equity for Māori, learner settings need to be culturally safe and welcoming for Māori learners, responsive to Māori learner perspectives and voices. A number of the interview questions sought to ascertain the extent to which Māori culture and language, the interviewee's Māori identity, and kaupapa Māori approaches to research were valued within the MPP and DPP frameworks. An important factor in the success of the programme is the facilitators' ability to manaaki (care for) the learners' underpinning cultural beliefs, and to respect and affirm Māori learner identity. Facilitators are responsible for ensuring that the learning environment incorporates tikaka-a-iwi and te reo-a-iwi throughout the programme and assessment processes. Generally speaking, interviewees felt that their facilitators and academic mentors had valued their Māori language, culture and unique relationships with the socio-cultural context.

Yes. My facilitator's actually been very responsive to my cultural needs, my language needs and my learning style. So, that has been quite a supportive role from my facilitator. Also, being able to perform pastoral care if needed, constant communication and accountability. I need constant communication to remind me that I have this mahi that I need to complete. I guess where my facilitator's gone above and beyond is being able to articulate some of the academic terminologies from a Western perspective and helped me understand it in a way that best fits my cultural perspective on my mahi... if you don't fit a particular Western model, to find a kaupapa Māori model that fits my thinking, and that's been reassuring for me.

Absolutely [I felt my culture, Identity and language were valued]. Yeah. I don't know if it would have been the same if I had different supervisors, but I know that there's things, even in my tiny little amount of reo that I have, that I don't have to explain, I didn't have to explain it to you, I didn't don't have to explain it to Jana. I don't know how she is on her reo journey, but what l'm using, she understands. And even my facilitator knows some of the words in his own way.

Even the interviewee who reported having poor experiences with her facilitator outlined that they believed the facilitator possessed some cultural competence. This shows a willingness from the facilitator to engage in a relationship based on ako, where s/he could position themselves as having something to learn from the student, whilst maintaining high expectations of Māori learner success.

I think, in part, yes. My facilitator was culturally sensitive and she had a cultural awareness, so I think at the beginning, yeah, absolutely. And she did have high expectations. Yes, she did.

For one learner, their journey into te ao Māori was initiated through the Māori research consultation process and the willingness to open themselves to their cultural located-ness within their research journey. This can be a vulnerable aspect of learning, where students explore who they are, where they are from, how this has shaped and informed their learning styles and life to date. Here the facilitator can play a pivotal role in consciously unlocking the richness and diversity that Māori learners bring with them. 
I didn't go anywhere near te ao Māori space at all [during my masters]. And that was not a reflection of the processes, it was a reflection of my state of mind. In that particular point in time, in my doctoral work, when I had to do the KTO [the Kaitohutohu Office] consultation², I met up with Kare. Ah, I was, yeah, she presented things, which were stimulus for me, because I wasn't going to go into that space. And then later on, they sort of manifested into like, I'm going in this space, you know, l'm new to that, but that's cool. I can own that. So, I think it was wonderful, that it was not forced upon, but it was nurtured and fostered.

Yes [my unique relationship with the socio-cultural context were acknowledged]. Yep. I'm going to say so. The project that I was working on and the learnings that I was bringing, and the way that I wanted to tell this story through narrative, and a large part of that narrative was centred on the Titit Islands. So, with that, my facilitator and academic mentor were keen... So, with that centring both my, the beginning of my knowledge acquisition that led into this, but also the importance of the narrative that informs the narrative but also informs myself, my own identity, I think that was definitely acknowledged and that was allowed to flourish through the project.

It is important to note that the foregoing quotations speak to interviewees' perceptions of individual facilitators. While interviewees believed the facilitators they worked with acknowledged and valued Māori identity and approaches to research, some pointed out that facilitators did not necessarily have a depth of knowledge, skill or experience working in te ao Māori to truly guide a learner via kaupapa Māori principles. Moreover, there are structural issues that currently prevent the learning experience of Māori being optimised. These are discussed in the immediately following section on how to optimise Māori learner experiences.

\section{OPTIMISING THE EXPERIENCE OF MĀORI}

To support equitable access and stronger Māori participation in their postgraduate studies, Māori learners were asked what was the optimal provision for their learning needs through Capable NZ. Interviewees were asked to think of ways in which the learning experience of Māori participating in the MPP or DPP programmes could be optimised. Suggestions include greater embedding of te reo Māori, the production of course materials and assessment regimes that better recognize non-Western forms of knowledge, greater face-to-face interactions with staff and Māori peers regarding study, as well as better resourcing of Māori staff and learners. These are discussed below.

\section{TE REO MĀORI AND BILINGUAL MATERIALS AND PROCESSES}

Te Tiriti o Waitangi calls for tertiary institutions to deliver an education system that enables and supports learners to acquire their qualification in te reo Māori.A common recommendation was that te reo Māori be further embedded within Capable NZ's frameworks, systems and practices. This includes producing materials and processes, such as admission forms, learner agreements and ethics procedures, that incorporate te reo Māori and recognise taha Māori. One of the following four paragraphs are from one interviewee, and although the quotes are lengthy, they are included here as the interviewee speaks to the need to include te reo Māori in Capable NZ's/Otago Polytechnic's processes and their personal efforts to achieve this. 
So, if we're going to be providing future Māori learners who are aspiring to do their mahi in te reo Māori, then, to provide them with the optimal opportunity and experience, there needs to be strong, robust processes around supporting those Māori learners who are wanting to do it in te reo Māori.

And if Māori learners are wanting to write in te reo Māori, then they need to be supported by people who enable them and inspire them to do that mahi in te reo. Me personally, l've found that there are gaps in the system. I personally wanted to submit my mahi in te reo, and then l've started finding areas where they need better support. For me, it's important to make people aware that te reo is a taonga, and it should be treated like a taonga, and it should be resourced adequately.

I wanted to bring to light some of the areas that we needed to be better on in the future.

The efforts of the individual described above seem to have empowered other learners to further incorporate te reo Māori in their own studies and brought about some change at an institutional level.

Tāne presenting his ethics in te reo has upped the awareness in the Ethics Committee and, of course, I only know that being on the Committee, but now I feel more comfortable that I can use what reo I have in my application. And we've just confirmed at the last meeting, that it can be an oral submission alongside the written. So, you still have to do written, but if you wish to speak to it, you can.

Another interviewee echoed the sentiment that some course materials, such as learning agreement forms, by virtue of exclusively using the English language, promote a Western worldview.

... at a more pragmatic day to day level, my only comment would be, and l've been vocal on this, as I'm not sure if, you know... [I've] never been a fan of the learning agreement, the template in particular. I think it starts the first line on it is "name". And I've always said that just summarises the Western worldview. It's like, it's not just a name, it's like, who am I, you know, it sets the scene.

Again, highlighting the connection between te reo Māori and taha Māori, one interviewee noted the importance of including te reo Māori in an appropriate way, a comment that speaks to the need for adequate resourcing if te reo Māori is to be further embedded in Capable NZ's processes.

....we need to start using it [te reo Māori] more and claiming more as a national language, but I temper that by saying that the reo that we use needs to be appropriate and specific. So, it needs to to match the context, it can't just be a dictionary definition of the reo. So, definitely needs to be more embedded, all through everything that we do and all through our programs, but there has to be a solid understanding of what those words are within context... 


\section{PRODUCTION AND ASSESSMENT OF KNOWLEDGE}

The call to prioritise te reo Māori and mātauraka Māori embedded and visible within the programme is a shared perspective. In a similar vein to those comments regarding the production of course materials that incorporate te reo Māori and recognise Māori culture, some participants also advocated for allowing assessment methods that recognised alternative means of knowledge production and presentation. These interviewees raised the question of whether, for example, waiata or karakia might be an acceptable way of presenting one's research for assessment.

And some of them [sources of optimisation] are beyond Capable's control. It's at a real meta level. And this is beyond Capable. But I think for Māori, to, to be able to express knowledge in ways that goes beyond the normative conventions. So why do Māori continue to be forced to write theses, you know. Why? Why can't they acknowledge, you know, be oral, be recorded, be expressed in whatever form, you know? There's so many forms of communication, you know? Waiata, everything goes on and on.

... that end thing that's being that's being questioned, or being examined, whatever that is. That should be a way that the participant is comfortable... I sort of wondered when I was thinking about all this stuff if you could actually be examined in karakia. Now, that's pretty, that's pretty outside of the box but the reason I thought that is that, you know, telling a short narrative and then a karakia. And that karakia, aligning everything with the knowledge system that you have, but also influence on practice. So, if for example, my thesis was about the Titi Islands, just having karakia that said "This is about the land, this about the sea, this is about the bird." The person examining that would have to have the skills to hear that karakia know what that person's talking about, would also have to know the skills or have the ability to know that that person knew how to put that into practice but then also knew where that knowledge comes from...

As the latter of these two quotations highlights, allowing for assessment via these methods would require that the assessors examining the material are appropriately skilled and knowledgeable assessors, able to identify and look for evidence of meeting the graduate profile in multiple ways. This speaks to the need for investing resources in not only building a wider pool of skilled and experienced Māori staff, but also forming closer connections and relationships with mana whenua throughout Aotearoa to provide a supportive korowai for supporting Māori learners throughout the motu. A strong Te Tiriti o Waitangi led model would provide a foundation to provide meaningful and authentic partnerships, programmes and processes. Furthermore, the specificity of kaumātua, who are holders of wisdom and knowledge may be required in order to assess karakia, mōteatea, waiata and tauparapara, for example. This highlights that point that Māori are not homogenous, that iwi specific knowledge is important and diversity and cultural richness is affirmed, valued and respected, as suggested by the following learner:

It may also be a case of utilising mana whenua relationships to include the people who have the knowledge to assist with the examinations etc. These are not OP staff, but kaumātua who are steeped in the tikaka and mätauraka of the particular subject - "expert commentators" if you like. This would be more appropriate I think and demonstrate true treaty partnership in education - maybe the examination criteria could be changed to reflect this? 


\section{BUILD RELATIONSHIPS AND EXPECTATIONS}

The previous "Relationships Beyond the Learner-Facilitator-Mentor Relationship" already builds a case for the importance of Māori learners having appropriate support networks in place to support their studies. Such sentiments can be further iterated and should be considered a recommendation stemming from the interviewees' commentary.

I think, I think just the idea of maybe seeing if there's other Māori learners that want to catch up with other Māori Learners. So, some sort of coffee kōrero either on the ground or on a Zoom or something. That would be awesome. Especially because I guess we're all around Aotearoa, can be difficult to meet in person but there might be other people out in Dunedin that are not at the Polytech that we could really have a zhoosh from, a reciprocal zhoosh.

... it's so deeply embedded in Māori epistemology and everything that whole, you know, how do you build and nurture and foster authentic relationships in a way that you feel safe and secure and stuff?

Notably, this relationship building helps to set expectations for the study more broadly and is, therefore, particularly important at the outset of one's studies.

Well, I've benefited from the various different hui that we've had. So, anything to do with research or ethics or just like the Symposium. We haven't had many this year, but last year, that's all part of that getting in the zone. So, if anyone can, either by Zoom or, preferably, you know, what we do face to face as much as possible. I guess what would you call that? Like a whakawhanaungatanga hui time, I guess, or a research hui time... And I haven't done this, but maybe it's something that could be beneficial, would be like a wee, I guess that's what the symposium could be for, but like a past graduates' symposium or hui. A booklet or something?

The ability to have that face to face contact. I would have really liked to have sit down with my facilitator and mentor and have a really good conversation about the whole program in what it means for me. I wasn't given the opportunity to actually have someone sit down and explain the process and what it actually involves, very different to undergrad world. And I would have liked to have been scaffolded through there, because I was so guns blazing when we started. I mean I kind of thought wow, this is a whole different level and I kind of wasn't really prepared. Almost like it would have been really cool to have like a wānanga almost, or something similar, just to kind of pull everyone and make some links.

Finally, one interviewee links the importance of whanaukataka with general time constraints and pressure. Work and family commitments often compete with time to complete a MPP or DPP, for all learners. However, for Māori learners, a certain amount of time is required to appropriately make connections with relevant people.

Dedicated FTE [would be helpful in my studies]. Absolutely. I mean, that's probably the biggest one in terms of, whanaungatanga takes time and I'm already thinking about that in terms of the project. OK, so I'm really knowing that I have to keep who I talk too small so I can do it in a meaningful way. And that's a limitation when there's not time you know. And also, if I'm working in this area, knowing that other people, other Māori will have time poor commitments, time, you know what I mean? Like, they'll be real busy too. So, I don't want to be mucking around with anyone's time. 


\section{HIGHLIGHTS OF THE MPP AND DPP FRAMEWORKS}

While the commentary in the foregoing section makes a clear case for potential optimisation of Māori learner experience through Capable NZ, it is worth reiterating that the majority of respondents spoke highly of their experience in the MPP or DPP programmes. Much of this was underpinned by the flexibility and autonomy that the Capable framework allowed for, especially regarding the ability to draw on both experiences outside of formal education contexts and non-Western (or non-Western academic) approaches to education.

...I believe in education, the high-performance sense, that allows you to grow as an individual being in control. And what you see is mean to your community... So I think that's where the Capable processes and philosophies really resonate with me... the traditional ivory tower of university knowledge... I think there's knowledge that it excludes and I think at least Capable is a welcoming alternative because, because it's a similar, you know, it's very similar to that the road, you know, Graham Smith had to go down with kaupapa Māori, you know? Like when he had to establish, you know, like in the academy and I feel Capable was doing the same with professional knowledge.

I guess, finding a qualification that enabled me to do what I wanted to do the way I wanted to do it... it's been the opportunity to explore that has been the biggest highlight. And, and being able to be a bit agile and change. So, you know, sort of going off in a direction thinking, "Actually, that's not where I want to be"... I like that.

So, for me, the ability to use reflective tools, but also to use that past theoretical and practical experience that l've had outside of structured learning environments [have been highlights]. The ability to use that as part of the research and as part of both the, the understanding of the research methodology, but also including that in the narrative of the research. So, I suppose that whole of all of learner approach, right from the very start of learning.

Even the respondent whose own experience of Capable NZ was not so positive, states that they appreciate the kaupapa and believe that it works for Māori. It simply happens that their experience was not as beneficial.

Don't get me wrong, I love what they do and everything they stand for, you know. I'm a product of that. And even though it just hasn't worked out for me, it does not take away from the fact that what, what you do and what you provide for our people, it gives them an amazing opportunity to validate everything about them. I haven't gone out and, you know, rubbished the whole Master's program, I'm not about that. It's not what l'd like to do, I guess, that was my story and it doesn't have to be the end of my journey but for now, l've just kind of kept there. l've got one of my social workers that is doing her Master's and just finished course one through us. And she is, she's actually inspired me, you know she's just finished course one and got her course review, and she just so excited and I love that. In a sense, that is what Capable is all about. I think it may have been different for me if I wasn't employed by them, as one of your staff members. 


\section{CONCLUSION}

This research set out to explore the optimal learning conditions for Māori postgraduate learners with Capable NZ. Within this research, Māori learner voice has been privileged, spotlighting their experiences and providing rich insights into their learner journey. Their feedback provides seeds of opportunity to ensure that Capable NZ responds to the needs and aspirations of Māori learners, whānau, iwi and hāpori Māori. Interviewees generally report positive experiences with Capable NZ and, in particular, the individual facilitators and academic mentors they have worked with throughout their studies. Much of this is based on a sentiment that facilitators and academic mentors typically valued Māori identity and culture, as well as what that might mean for a learner's relationship with the socio-cultural context in which they operate and the research methodologies a learner might employ. Only one respondent reported that they had not been able to arrive at a productive, supportive working arrangement with some of Capable NZ's facilitators/mentors. On the whole, the Capable NZ's framework was seen as allowing for individual autonomy. For Māori learners, this meant being able to draw on skills, knowledge and experience from outside of formalised education, particularly where their approach to their studies would be informed by te ao Māori, rather than traditional Western approaches to education.

\section{Suggestions for Change Practice}

Yet, it is clear from the commentary that there is room for optimisation and that interviewees are relatively well aligned as to where this optimisation could take place. Improvements were typically pitched at an institutional level, rather than in relation to the performance of particular facilitators. As outlined above, key areas for optimising Māori learner experience include:

I. Māori thrive in Māori Medium Education settings. Access to Māori medium pathways in Capable NZ need to be improved. Embedding te reo Māori in materials and processes within the Capable NZ framework is also required.

2. Māori want tino rakatirataka, agency and authority over their own learning. This requires developing learning templates and assessment methods that recognise and uphold Māori forms of knowledge production.

3. Developing a greater sense of belonging is crucial for Māori to succeed as Māori through wider Māori support networks. This includes peer support for learners, developing a tuakana-teina process. It also means ensuring learners have their own Māori support space to support the development of their cultural identity and to maintain cultural safety, not just academic achievement.

4. Learning and teaching needs to reflect identity, culture and values. Establishing Māori support networks not only assists the learner, but also creates a kaupapa Māori space for Māori, by Māori and with Māori. It also provides an avenue for Māori to informally engage in whakawhanaukataka, learn more about their own and other learner's whakapapa and to enjoy a culturally safe Māori peer-peer space outside of the learnerfacilitator relationship. Such networks also assist facilitators and mentors, as facilitators/mentors cannot be expected to hold all the requisite knowledge and skills.

5. The recruitment and hiring of Māori staff that are representative of and responsive to Māori, and who hold an understanding of culturally responsive and inclusive practices is vital. Within the cultural collective, include kaumātua as a valued source of wisdom, advice and guidance, and embed a process for acknowledging their contribution and mana.

All of these areas of potential optimisation require greater resourcing. Interviewee commentary suggests that this could include, but is not limited to: (i) greater support for Māori staff already employed by Capable NZ and advocating for Māori learners; (ii) the hiring of additional staff to support Māori learners and add to the body of 
institutional knowledge that exists regarding te ao Māori; (iii) the provision of more education regarding te ao Māori to existing staff. No doubt, financial resources will be required, but this should also be seen as upholding Te Tiriti commitments for equitable learning programmes that are tailored to fit the cultural and educational needs of Māori. Partnering with kaumātua and iwi also provides a korowai of cultural safety for learners (and facilitators), as well as contributing and valuing authentic relationships. In implementing any changes, it is important that change is driven due to a genuine belief in the kaupapa of optimising Māori learner experience. It will also require a prioritisation of resources and strategic manoeuvring to reflect culturally responsive postgraduate programmes that culturally fit the aspirational needs of Māori learners, iwi and hāpori Māori. This will require a deliberate and systematically coherent approach to readjusting current practices to grow Māori service provision, giving practical effect to Te Tiriti - Waitangi as a primary objective.

Mā te huruhuru ka rere te manu / Adorn the bird with feathers and it will fly.

Dr Kelli Te Maihāroa (https://orcid.org/0000-0002-9586-0657) has a background in education and social services, with a focus on kaupapa Māori initiatives and bi-cultural responsiveness. She sees education as the number one lever to address equity issues and the potential to transform peoples' lives. At Otago Polytechnic Kelli holds the role of Kaihautū: Te Kāhui Whetū / Executive: Capable Māori, working with Iwi Māori throughout Aotearoa New Zealand. She is an active member within her whānau, hapū, iwi and local Māori community. Kelli is a grandchild of Te Maihāroa, the last southern Māori prophet and tohuka (expert tribal specialist). Her area of research interest are indigenous peace traditions, indigenous research, cultural revitalisation and Māori educational initiatives. Kelli co-edited with Heather Devere and John Synott (eds.) Peacebuilding and the Rights of Indigenous Peoples: Experiences and Strategies for the 2 Ist Century, (Cham, Switzerland: Springer, 2016).

Dr Griffin Leonard (Te Arawa) completed his PhD at the National Centre for Peace and Conflict Studies, University of Otago. His research focused on US foreign policy and employed a mixed methods approach. Following his studies, Griffin worked as an independent researcher and data analyst, often working with staff at Otago Polytechnic and the University of Otago. This work was varied, ranging from the health sciences to strategic framework implementation and curriculum development. Griffin now works within the Shared Services Division at the University of Otago.

Tonga Karena He paenga rimurimu noa iho tēnei ki te ngutuawa o Kōteoteo, ā, mātai te titiro ki Te Umuroa, ki Nukuteapiapi ki te awa o te Mauhanga ki te whenua haumako o Ngāti Kahumate, o ā Tara, āTūhekerangi, ā Tamarongo, ko ā Haumia, ōku karangatanga hapū. Rere whakauta ki Parihaka papa kāinga ko Parāhuka, ko Takitūtū, ko Toroānui,he tūranga marae he tūranga tangata, tau atu rā ki ngā whare āio mōwai rokiroki o Te Niho o Te Ātiawa, o Te Paepae o te Raukura me te Mahi Kū-are ē - he whakairinga kupu, he whakairinga rau kawakawa ē. Ko au tēnei, he uri o Taranaki lwi i heke mai i ngā puna ora o Rua-Taranaki. I ēnei rangi nei he whakaihoiho kōrero taku mahinga nui; he tauawhi i haku hoa kaimahi kia mārama ai ki te tūranga tāhūhū o ngā tikanga o Taranaki me tōna reo. Tērā e taea ai te mātoro atu ki te taiao ki te whakakaupapa i te reo me ngā tikanga hei purutanga mouri kia manawa toka ai ngā herenga-ā-iwi, kia manawa tina ai ngā herenga whenua. Ko tō te mahi whakaūkaipo i te reo - me mātua whakaūkaipō i te tangata. Ana, koia tērā te pūtahitanga o te whakaaro nui e arohia ake nei ki roto i haku mahi ki Parininihi ki Waitōtara. He awhi, he manaaki, he tautoko, he tuku i te mouri ora o te kōrero kia rere kia tarāwharetia ai.Tēnā koutou katoa. 
I Ministry of Education, "Ka Hitikia - Ka Hāpaitia |The Māori Education Strategy (English)," https://www.education.govt.nz/ourwork/overall-strategies-and-policies/ka-hikitia-ka-hapaitia/ka-hikitia-ka-hapaitia-the-maori-education-strategy/

2 The Kaitohutohu Office provides consultation from mana whenua to support researchers. This consultation is a part of the ethics process at Otago Polytechnic.

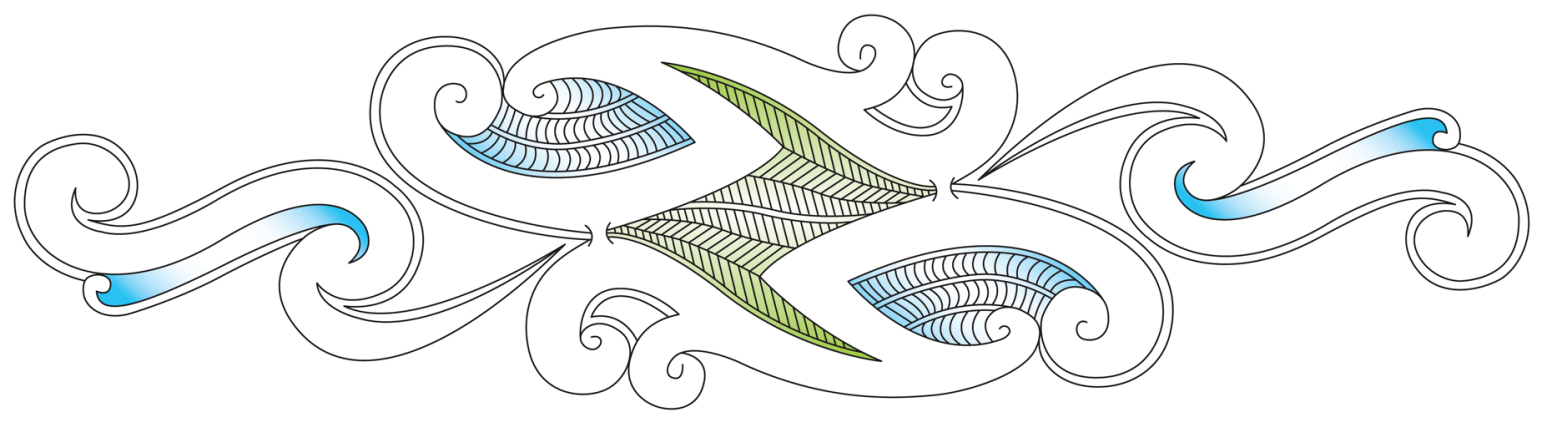

